\title{
Nesfatin-1 $1_{30-59}$ but not the $\mathrm{N}$ - and C-terminal fragments, nesfatin-1 $1_{1-29}$ and nesfatin-1 $\mathbf{1}_{60-82}$ injected intracerebroventricularly decreases dark phase food intake by increasing inter-meal intervals in mice
}

\author{
Andreas Stengel ${ }^{a, b}$, Miriam Goebel-Stengel $^{a, c}$, Lixin Wang ${ }^{\mathrm{a}}$, Ikuo Kato ${ }^{\mathrm{d}}$, Masatomo Morie, \\ and Yvette Tachéa \\ ${ }^{a}$ CURE/Digestive Diseases Research Center, Center for Neurobiology of Stress, Digestive \\ Diseases Division, Department of Medicine, University of California Los Angeles and Veteran \\ Affaires Greater Los Angeles Healthcare System, Los Angeles, CA USA \\ bDepartment of Medicine, Obesity Center Berlin, Division Psychosomatic Medicine; Charité \\ Universitätsmedizin Berlin, Campus Mitte, Berlin, Germany \\ 'Department of Internal Medicine, Institute of Neurogastroenterology and Motility; Martin-Luther \\ Hospital, Academic Teaching Institution of Charité - University Medical Center, Berlin, Germany \\ dDepartment of Bioorganic Chemistry, Faculty of Pharmaceutical Sciences, Hokuriku University, \\ Kanazawa, Japan \\ eDepartment of Medicine and Molecular Science, Gunma University Graduate School of \\ Medicine, Maebashi, Japan
}

\begin{abstract}
Nesfatin-1 is an 82 amino acid N-terminal fragment of nucleobindin2 that was consistently shown to reduce dark phase food intake upon brain injection in rodents. We recently reported that nesfatin-1 $1_{1-82}$ injected intracerebroventricularly (icv) reduces dark phase feeding in mice. Moreover, intraperitoneal injection of mid-fragment nesfatin-1 (nesfatin-1 ${ }_{30-59}$ ) mimics the food intake-reducing effects of nesfatin- $1_{1-82}$, whereas $\mathrm{N}$-terminal (nesfatin-1 ${ }_{1-29}$ ) and C-terminal fragments (nesfatin-1 ${ }_{60-82}$ ) did not. We therefore characterized the structure-activity relationship of nesfatin-1 injected icv to influence the dark phase meal pattern in mice. Mouse nesfatin- $1_{1-29}$, nesfatin- $1_{30-59}$, nesfatin-1 $1_{60-82}$ or vehicle was injected icv in freely fed C57B1/6 mice immediately before the dark phase and food intake was monitored using an automated episodic feeding monitoring system. Nesfatin-1 $1_{30-59}(0.1,0.3,0.9 \mathrm{nmol} /$ mouse $)$ induced a dose-related reduction of 4 -h food intake by $28 \%, 49 \%$ and $49 \%$ respectively resulting in a $23 \%$ decreased cumulative 24 -h food intake compared to vehicle $(p<0.05)$. The peak reduction occurred during the $3^{\text {rd }}(-96 \%)$ and $4^{\text {th }}$ hour $(-91 \%)$ post injection and was associated with a reduced meal frequency (0-4h: $-47 \%)$ and prolonged inter-meal intervals (3.1-times) compared to vehicle
\end{abstract}

Address for correspondence: Yvette Taché, Ph.D., Center for Neurobiology of Stress, CURE Building 115, Room 117, VA GLA Healthcare System, 11301 Wilshire Blvd, Los Angeles, CA, 90073, USA, Tel: +1 310312 9275, Fax: +1 3102684963 , ytache@mednet.ucla.edu.

Disclosure

The authors have nothing to disclose. No conflicts of interest exist.

Publisher's Disclaimer: This is a PDF file of an unedited manuscript that has been accepted for publication. As a service to our customers we are providing this early version of the manuscript. The manuscript will undergo copyediting, typesetting, and review of the resulting proof before it is published in its final citable form. Please note that during the production process errors may be discovered which could affect the content, and all legal disclaimers that apply to the journal pertain. 
$(p<0.05)$, whereas meal size was not altered. In contrast, neither nesfatin- $1_{1-29}$ nor nesfatin- $1_{60-82}$ reduced dark phase food intake at equimolar doses although nesfatin- $1_{60-82}$ prolonged inter-meal intervals $(1.7$-times, $p<0.05)$. Nesfatin- $1_{30-59}$ is the active core of nesfatin- $1_{1-82}$ to induce satiety indicated by a reduced meal number during the first $4 \mathrm{~h}$ post injection. The delayed onset may be indicative of time required to modulate other hypothalamic and medullary networks regulating nocturnal feeding as established for nesfatin-1.

\section{Keywords}

food intake; meal pattern; mouse; nesfatin-1 fragments; satiation; satiety

\section{Introduction}

Nesfatin- 1 is an 82-amino acid polypeptide that was discovered recently by Oh-I and coworkers [10]. The precursor protein nucleobindin2 (NUCB2) was detected in the rat hypothalamus and can be potentially processed into nesfatin-1, nesfatin-2 and nesfatin-3 [10]. Only nesfatin- 1 was shown to reduce food intake following injection into the third ventricle of rats, whereas injection of nesfatin-2 or nesfatin-3 had no effect [10].

Subsequently, the inhibitory effect of nesfatin- 1 on dark phase feeding after brain injection at the level of the lateral, third or fourth brain ventricle or into the cisterna magna in rats was confirmed and extended by several other research groups $[7,8,14,18,19]$. Recently, these findings were expanded to another species showing the anorexigenic action also in mice following injection into the lateral or third brain ventricle [5, 8]. When brain NUCB2 signaling was blocked by the use of an anti-NUCB2 antisense oligonucleotide daily food intake, and consecutively body weight gain of rats were increased [10] supporting a physiological role of NUCB2/nesfatin-1 as anorexigenic modulator of food intake.

Despite the growing spectrum of activity in the central nervous system induced by nesfatin-1 $[11,16]$, the receptor mediating these actions is still unknown. Shimizu and colleagues designed three nesfatin- 1 fragments, nesfatin- $1_{1-29}$, nesfatin- $1_{30-39}$ and nesfatin- $1_{60-82}$ based on the predicted secondary structure of nesfatin- 1 and showed in mice that nesfatin-1 ${ }_{30-39}$ injected intraperitoneally reduces dark phase food intake whereas nesfatin- $1_{1-29}$ and nesfatin- $1_{60-82}$ did not [13] thereby pointing to the active core of nesfatin-1. However, when injected peripherally much higher doses of the fragment (2000times) had to be applied compared to the effective doses of full length nesfatin- 1 injected into the lateral brain ventricle of mice $[13,14]$. Whether this is due to the short half life of the fragment itself by this route of administration or accessibility to the site of action is not known.

In order to assess the mechanisms regulating food intake the analysis of food intake microstructure is of high relevance [4]. It was recently shown that full length nesfatin-1 injected intracerebroventricularly (icv) reduces dark phase feeding in mice by reducing meal size and prolonging inter-meal intervals thereby increasing satiation and satiety respectively [5]. To get insight to the structure-activity component of icv injected nesfatin-1's underlying satiation and satiety effects in mice, we investigated whether nesfatin- $1_{1-29}$, nesfatin- $1_{30-59}$ and nesfatin- $1_{60-82}$ injected icv influence food intake in ad libitum fed undisturbed mice and analyzed changes in meal patterns using an automated food intake monitoring system we recently validated for mice [15]. 


\section{Materials and Methods}

\subsection{Animals}

Male adult C57B1/6 mice (aged 6-8 weeks, Harlan Laboratories) were first group housed 4/ cage under controlled illumination $(06: 00-18: 00 \mathrm{~h})$ and temperature $\left(21-23^{\circ} \mathrm{C}\right)$ and then habituated to single housing in food intake monitoring cages as detailed below. Mice had ad libitum access to purified standard rodent diet (AIN-93M, Research Diets, Inc., Jules Lane, New Brunswick, NJ) and tap water. All protocols were approved by the Veterans Affairs Institutional Animal Care and Use Committee (\# 99127-07).

\subsection{Peptides}

Mouse nesfatin- $1_{1-29}$, nesfatin- $1_{30-59}$ and nesfatin- $1_{60-82}$ were synthesized as previously described [13] and purity assessed by HPLC and mass spectrometry. The peptides were stored in powder form at $-80^{\circ} \mathrm{C}$ and weighed and dissolved in pyrogen free double distilled water immediately before administration.

\subsection{Intracerebroventricular injection}

The icv injections $(5 \mu \mathrm{l})$ were performed before the dark phase starting at 18:00 $\mathrm{h}$ under short isoflurane anesthesia (2-3 min, $4.5 \%$ vapor concentration in oxygen; VSS, Rockmart, GA) as described in our previous studies in mice $[5,9]$. The injection site was localized at the apex of the equal triangle between the eyes and the back of the head. This site was thoroughly cleaned with Povidone-Iodine 10\% (Aplicare Inc., Meriden, CT) and the skull punctured manually with a 30-gauge needle equipped with a polyethylene tube leaving 4$4.5 \mathrm{~mm}$ of the needle tip exposed and attached to a Hamilton syringe. The accuracy of the injections was confirmed in our previous studies by injecting cresyl violet dye under similar conditions into the lateral brain ventricle of 50 mice [9]. On average, mice completely recovered from anesthesia within 5 min.

\subsection{Automated food intake monitoring}

The BioDAQ episodic food intake monitoring system (BioDAQ, Research Diets, Inc., New Brunswick, NJ) was used to investigate the food intake microstructure in mice as described in our previous studies $[5,15,17]$. Mice were fed a purified regular rodent diet (AIN-93M, Research Diets, Inc.) starting at 4 weeks of age as that this diet causes less spillage than standard Prolab diet (Prolab RMH 2500; LabDiet). Mice were habituated to single housing in the food intake monitoring apparatus for one week before the first experiment. Cages had the same size as the group housing cages and contained a similar amount of bedding and the same intracage enrichment device (houses) as well as ad libitum access to chow pellets through a low spill food hopper placed on a balance. On average, mice habituated to the new conditions within 3-4 days and then displayed stable food intake and body weight gain. Water was provided ad libitum using regular water bottles.

The BioDAQ food intake monitoring system established for the use in mice in our previous studies $[5,15,17]$ weighs the hopper with food $( \pm 0.01 \mathrm{~g})$ every second and detects "not eating" as weight stable and "eating" as weight unstable. Feeding bouts defined as changes in stable weight before and after an event are recorded as vectors with a start time, duration, and amount consumed. These bouts are separated by an inter-bout interval (IBI) and a meal consists of one or more bouts. Meals are separated by inter-meal intervals (IMI). The IBI was defined as $5 \mathrm{sec}$ and the IMI as $5 \mathrm{~min}$. The minimum meal size was defined as $0.02 \mathrm{~g}$ and therefore food intake was considered as one meal when the feeding bouts occurred within $5 \mathrm{~min}$ of the previous response and their sum was equal to or greater than $0.02 \mathrm{~g}$. If feeding bouts were more than 5 min apart they were considered a new meal. Meal parameters assessed in this study encompassed meal frequency (number/period), bout 
frequency (number/period), meal size (g/meal), meal duration (min/meal), total meal time ( $\mathrm{min} /$ period), time spent in meals (\%/period), inter-meal interval (min), latency to the first meal ( $\mathrm{min})$, duration of the first meal $(\mathrm{min})$, eating rate of the first meal $(\mathrm{mg} / \mathrm{min})$, eating rate/period $(\mathrm{mg} / \mathrm{min})$ and the satiety ratio. These parameters were calculated by the software provided by the manufacturer (BioDAQ Monitoring Software 2.2.02) and the satiety ratio was obtained by dividing the average inter-meal interval by the average meal size ( $\mathrm{min} / \mathrm{g}$ food eaten).

\subsection{Food intake experiments}

Mice fed ad libitum and habituated to single housing were injected icv with nesfatin- $1_{30-59}$ $(0.1,0.3$, or $0.9 \mathrm{nmol} / \mathrm{mouse})$ or vehicle ( $5 \mu 1$ of pyrogen-free double distilled water) at the onset of the dark phase and food intake microstructure was assessed over a period of $24 \mathrm{~h}$. Doses were based on our previous study showing a reduction of dark phase feeding following icv injection of $3 \mu \mathrm{g}(\sim 0.3 \mathrm{nmol}) /$ mouse nesfatin- $1_{1-82}$ [5]. After establishing a dose of $0.3 \mathrm{nmol} /$ mouse nesfatin- $1_{30-59}$ as effective dose to reduce dark phase food intake in mice, we performed additional studies injecting nesfatin- $1_{1-29}$ and nesfatin- $1_{60-82}$ at equimolar doses of $0.3 \mathrm{nmol} / \mathrm{mouse}$ or vehicle at the onset of the dark phase and assessed food intake microstructure over a period of $24 \mathrm{~h}$. All experiments were repeated in a crossover design.

\subsection{Statistical analysis}

Data are expressed as mean \pm SEM and were analyzed by one-way analysis of variance (ANOVA) followed by Tukey post hoc test or two-way ANOVA followed by the HolmSidak method. Differences between groups were considered significant when $p<0.05$.

\section{Results}

\subsection{Nesfatin-1 $30-59$ injected intracerebroventricularly before the dark phase reduces food intake by altering the feeding microstructure}

Nesfatin- $1_{30-59}(0.1,0.3$ and $0.9 \mathrm{nmol} / \mathrm{mouse}, \mathrm{icv})$ induced a dose-related decrease in dark phase food intake during the first $4 \mathrm{~h}$ post injection compared to vehicle $(\mathrm{g} / 4 \mathrm{~h}: 0.44 \pm 0.09$, $0.31 \pm 0.08$, and $0.31 \pm 0.07$ respectively vs. $0.61 \pm 0.04, p<0.01$; Fig. 1 ). Since the dose of $0.3 \mathrm{nmol} /$ mouse nesfatin- $1_{30-59}$ was the lowest dose inducing a significant reduction of feeding this dose was used in further analyses. The analysis of hourly food intake following injection of nesfatin- $1_{30-59}$ showed that compared to vehicle, the reduction of dark phase food intake occurred during the $2-3 \mathrm{~h}(0.01 \pm 0.01 \mathrm{vs} .0 .15 \pm 0.04 \mathrm{~g} / \mathrm{h}, p<0.01)$ and $3-4 \mathrm{~h}$ periods $(0.01 \pm 0.01$ vs. $0.10 \pm 0.03 \mathrm{~g} / \mathrm{h}, p<0.05)$ post icv injection, whereas no significant effects were observed before or thereafter (Fig. 2A). Two-way ANOVA showed a significant influence of treatment $\left(\mathrm{F}_{(1,111)}=11.5, p<0.01\right)$ and time $\left(\mathrm{F}_{(7,111)}=2.8, p<\right.$ $0.05)$. The delayed onset of nesfatin- $1_{30-59}$ 's food intake reducing action was also reflected in the absence of changes in the parameters of the first meal including the latency to the first meal and its duration as well as the eating rate which were not significantly different from vehicle $(\mathrm{p}>0.05$; Table 1$)$.

In addition to the first $4 \mathrm{~h}$, the food intake monitored at separate 4 -h periods for 24 -h post icv nesfatin- $1_{30-59}$ injection was also reduced in the $4-8 \mathrm{~h}$ period compared to vehicle $(0.26$ \pm 0.08 vs. $0.69 \pm 0.16 \mathrm{~g} / 4 \mathrm{~h}, p<0.05$ ) but no longer thereafter (Fig. 2B). When displayed as cumulative food intake, the reduction was still significant at $24 \mathrm{~h}$ post nesfatin- $1_{30-59}$ injection compared to vehicle ( $2.14 \pm 0.21$ vs. $2.77 \pm 0.19 \mathrm{~g} / 24 \mathrm{~h}, p<0.05$; Fig. 2C). Twoway ANOVA indicated a significant influence of treatment $\left(\mathrm{F}_{(1,83)}=45.9, p<0.001\right)$ and time $\left(\mathrm{F}_{(5,83)}=50.6, p<0.001\right)$. 
Due to the fact that nesfatin- $1_{30-59}$ decreased food intake during $3^{\text {rd }}$ and $4^{\text {th }}$ hours post icv injection resulting in a reduced 4-h dark phase food intake, the food intake microstructure was analyzed for this 4-h period. Nesfatin- $1_{30-59}$ injected icv significantly decreased the meal frequency $(2.71 \pm 0.18$ vs. $5.14 \pm 0.26$ meals $/ 0-4 \mathrm{~h}, p<0.001$; Fig. 3A) and bout frequency (12.29 \pm 2.56 vs. $19.57 \pm 1.85$ bouts/ $0-4$ h, $p<0.001$; Fig. 3B) compared to vehicle, whereas the average meal size ( $0.12 \pm 0.03$ vs. $0.12 \pm 0.02 \mathrm{~g} / \mathrm{meal}, p>0.05$; Fig. $3 \mathrm{C})$ and meal duration $(14.83 \pm 3.07$ vs. $16.86 \pm 2.26 \mathrm{~min} / \mathrm{meal}, p>0.05$; Fig. 3D) were not altered. Nesfatin- $1_{30-59}$ also reduced the total meal time (39.56 \pm 8.79 vs. $85.23 \pm 9.92 \mathrm{~min} /$ $0-4 \mathrm{~h}, p<0.01$; Fig. 3E) and time spent in meals (16.48 \pm 3.66 vs. $35.51 \pm 4.13 \% / 0-4 \mathrm{~h}, p$ $<0.01$; Fig. 3F) compared to vehicle. Since meal frequency was reduced by nesfatin- $1_{30-59}$, inter-meal intervals were significantly prolonged compared to vehicle (113.04 $\pm 3.07 \mathrm{VS}$. $36.86 \pm 1.46 \mathrm{~min}, p<0.01$; Fig. $3 \mathrm{G}$ ). While the eating rate over the $0-4 \mathrm{~h}$ period was not altered by nesfatin $-1_{30-59}(3.79 \pm 0.92$ vs. $3.23 \pm 0.51 \mathrm{mg} / \mathrm{min}, p>0.05$; Fig. $3 \mathrm{H})$, the satiety ratio was significantly increased compared to vehicle $(1336.1 \pm 331.7$ vs. $321.3 \pm$ $30.8 \mathrm{~min} / \mathrm{g}$ food eaten, $p<0.05$; Fig. 3I).

\subsection{Nesfatin-1 $1_{1-29}$ and nesfatin-1 $60-82$ injected intracerebroventricularly do not alter dark phase food intake and do not robustly affect the microstructure of feeding}

Nesfatin- $1_{1-29}$ and nesfatin- $1_{60-82}$ were injected icv under the same experimental conditions using an equimolar dose of $0.3 \mathrm{nmol} /$ mouse. Since food intake was reduced mainly in the $3^{\text {rd }}$ and $4^{\text {th }}$ hour post injection of nesfatin- $1_{30-59}$ these periods were first analyzed after injection of nesfatin- $1_{1-29}$ and nesfatin- $1_{60-82}$. In contrast to nesfatin- $1_{30-59}$, icv injected nesfatin- $1_{1-29}$ and nesfatin- $1_{60-82}$ did not alter hourly dark phase food intake during the first $4 \mathrm{~h}$ post injection compared to vehicle ( $\mathrm{p}>0.05$; Table 2 ). Moreover, no modulation of hourly or cumulative food intake was observed at any time point during the 24-h observation period compared to vehicle icv (data not shown). In line with the lack of alterations in food intake, the food intake microstructure analyzed for the first $4 \mathrm{~h}$ post injection was mostly unaffected by nesfatin- $1_{1-29}$ and nesfatin- $1_{60-82}$ (Table 3 ). However, nesfatin-1 $1_{1-29}$ decreased the average meal duration compared to vehicle $(-44 \%, p<0.05)$, while nesfatin- $1_{60-82}$ reduced the bout $(-44 \%)$ and meal frequency $(-28 \%)$ resulting in prolonged inter-meal intervals compared to icv vehicle (1.7-times, $p<0.05$; Table 3$)$.

\section{Discussion}

In the present study we show that nesfatin- $1_{30-59}$ injected icv in mice decreases dark phase food intake, whereas nesfatin- $1_{1-29}$ and nesfatin- $1_{60-82}$ tested under the same conditions did not alter the hourly food intake. These data extend the previous findings showing that nesfatin- $1_{30-59}$ but not nesfatin- $1_{1-29}$ and nesfatin- $1_{60-82}$ reduce food consumption following intraperitoneal injection in mice [13]. The effect of nesfatin- $1_{30-59}$ was doserelated showing a decrease of 4 -h food intake by $28 \%$ and $49 \%$ following icv injection of 0.1 and $0.3 \mathrm{nmol} /$ mouse respectively with a plateau inhibitory response at a dose higher than $0.3 \mathrm{nmol} /$ mouse ( $49 \%$ inhibition at $0.9 \mathrm{nmol} /$ mouse). In our previous study we showed that full length nesfatin-1 injected icv in mice reduces dark phase 4-h food intake by $46 \%$ under similar experimental conditions with a minimum dose of $3 \mu \mathrm{g}(\sim 0.3 \mathrm{nmol}) /$ mouse [5]. These results show that equimolar doses of full length nesfatin- $1_{1-82}$ and nesfatin- $1_{30-59}$ induce a similar reduction of ad libitum dark phase food intake in mice establishing that nesfatin- $1_{30-59}$ is the active core of nesfatin-1's inhibitory action in the brain.

As observed before for the full length peptide, nesfatin- $1_{30-59}$ reduces dark phase food intake with a delayed onset and a maximum effect during the third (-96\%) and fourth hour $(-91 \%)$ post injection, whereas before and afterwards no significant change was observed. Further indication of a delayed onset of action came from the analysis of the first meal which had the same duration, was consumed at the same time and with the same eating rate 
when compared to vehicle. The delayed onset of anorexigenic action was reported before in rats that were injected icv through a chronic cannula without anesthesia [14] and in mice injected acutely under brief anesthesia [5]. The inhibition of food intake during the $3^{\text {rd }}$ and $4^{\text {th }}$ hour post icv injection of nesfatin- $1_{30-59}(0.3 \mathrm{nmol})$ translated into a long lasting reduction of cumulative food intake which was still observed after $24 \mathrm{~h}(-23 \%)$. In addition, when analyzed in 4-h intervals, nesfatin- $1_{30-59}$ not only decreased feeding during the first but also during the second 4-h period. In our previous studies, the full length nesfatin-1 (0.3 $\mathrm{nmol}$, icv) only reduced dark phase food intake during the first $4 \mathrm{~h}$ post icv injection translating into a reduction of 12-h cumulative food intake in mice [5]. It may be speculated that nesfatin- $1_{30-59}$ results in a stronger binding/signaling activation or availability at the yet unknown nesfatin-1 receptor. We previously assessed nesfatin-1's (5 pmol, icv) influence on behavior and nesfatin-1 did not induce alterations of locomotor activity or grooming (washing, licking, and/or scratching) behavior [14]. Similarly, in a recent report a higher dose of nesfatin-1 (25 pmol, icv) did not alter locomotor activity when assessed automatically in rats, while food intake was decreased for a sustained period of time [7]. Therefore, although not assessed in the present study in mice, existing evidence does not support that nesfatin-1's or nesfatin-1 $1_{30-59}$ 's anorexigenic action is secondary to alterations of locomotor activity.

Analysis of the feeding microstructure using an automated episodic feeding monitoring system showed that the nesfatin- $1_{30-59}$ induced reduction of food intake is due to a reduction in the number of meals associated with longer inter-meal intervals and an increased satiety ratio whereas meal sizes were not altered. This pattern indicates that nesfatin- $1_{30-59}$ increases satiety while not affecting satiation, a finding that differs from the action shown for full length nesfatin-1 which increases both, satiation (by reducing meal size) and satiety (by reducing the number of meals) [5]. Based on these data the fragment nesfatin- $1_{30-59}$ could interact with receptors other than the nesfatin-1 receptor or, as suggested above, display different binding and dissociation kinetics towards the same receptor. In a previous report it was shown that nesfatin- $1_{30-59}$ upregulates the mRNA expression of the anorexigenic brain peptides, proopiomelanocortin (POMC) and cocaineand amphetamine-regulated transcript (CART) [13] raising the possibility that these peptides contribute to the delayed anorexigenic effect. In addition, the anorexigenic effect of full length nesfatin-1 is blocked by third ventricular injection of the melanocortin receptors 3 and $4\left(\mathrm{MC}_{3 / 4}\right)$ antagonist, SHU9119 [10]. However, previous studies in rats demonstrated that icv or fourth ventricular injection of the $\mathrm{MC}_{3 / 4}$ receptor agonist, MTII reduced food intake by reducing meal size while not altering meal frequency [2,3] indicating an effect on satiation but not satiety. Conversely, mice lacking POMC showed a food intake pattern with increased meal sizes without alterations in meal frequency [12] further pointing towards an exclusive action of POMC on satiation, which does not mimic that induced by nesfatin-1 $1_{30-59}$. Likewise, icv injection of CART decreased the meal size for liquid food in rats whereas meal frequency remained unchanged [1] also suggesting an exclusive effect on satiation. These differential patterns of influence on feeding microstructure do not support that nesfatin- $1_{30-59}$ 's satiety inducing action is mediated by downstream POMC and CART signaling. In the first study on nesfatin- $1_{30-59}$, Shimizu et al. reported a structural similarity with the orexigenic peptide, agouti-related peptide (AgRP) which seems to be essential for the anorexigenic function since a mutation in this region abolished the food intake reducing effect [13]. However, since $\mathrm{AgRP}$ is an inverse agonist on the $\mathrm{MC}_{3 / 4}$ [6] effects opposite to POMC with reduced satiation would be expected, effects different from the alterations observed after nesfatin- $1_{30-59}$. Taken together, the stimulation of satiety with lack of effect on satiation observed after icv injection of nesfatin- $1_{30-59}$ may not engage the activation of POMC or CART or inhibition of AgRP. However, since the involvement of downstream POMC signaling contributes to full length nesfatin-1's anorexic action, this assumption will have to be corroborated in future investigations. 
One has to note that nesfatin- $1_{1-29}$ and nesfatin- $1_{60-82}$ despite the lack of effect on dark phase food intake following peripheral [13] and central (present study) injection affected single parameters of feeding microstructure. Nesfatin- $1_{1-29}$ reduced the average duration of a meal without altering meal size or any of the other parameters. On the other hand, nesfatin- $1_{60-82}$ exclusively reduced meal frequency associated with increased inter-meal intervals suggesting a stimulatory effect on satiety. However, since this did not translate in a reduction of food intake at any time point, the finding warrants cautious interpretation.

In conclusion, icv injection of nesfatin- $1_{30-59}$ in ad libitum fed mice induced a delayed onset of dark phase reduction of food intake whereas nesfatin- $1_{1-29}$ and nesfatin-1 $1_{60-82}$ had no effect. These results provide pharmacological evidence that nesfatin- $1_{30-59}$ is the active core peptide for the central action of full length nesfatin-1. As there are several arginines and lysines within the nesfatin-1 sequence, suggesting further processing by prohormone convertases or other processing enzymes, the present data support exploration as to whether nesfatin-1 processing in the brain results in the occurrence of nesfatin-1 $1_{30-59}$. The anorexigenic action of the peptide is due to an increased satiety without altering satiation through mechanisms yet to be characterized.

\section{Acknowledgments}

This work was supported by Veterans Affairs Research Career Scientist Award (Y.T.), R01 NIH DK-33061 (Y.T.), Center Grant DK-41301 (Animal Core and Supplement Grant, Y.T.) and Charité University Funding UFF 89-441-176 (A.S.).

\section{References}

1. Aja S, Schwartz GJ, Kuhar MJ, Moran TH. Intracerebroventricular CART peptide reduces rat ingestive behavior and alters licking microstructure. Am J Physiol Regul Integr Comp Physiol. 2001; 280:R1613-9. [PubMed: 11353662]

2. Azzara AV, Sokolnicki JP, Schwartz GJ. Central melanocortin receptor agonist reduces spontaneous and scheduled meal size but does not augment duodenal preload-induced feeding inhibition. Physiol Behav. 2002; 77:411-6. [PubMed: 12419417]

3. Berthoud HR, Sutton GM, Townsend RL, Patterson LM, Zheng H. Brainstem mechanisms integrating gut-derived satiety signals and descending forebrain information in the control of meal size. Physiol Behav. 2006; 89:517-24. [PubMed: 16996546]

4. Geary N. A new way of looking at eating. Am J Physiol Regul Integr Comp Physiol. 2005; 288:R1444-6. [PubMed: 15886354]

5. Goebel M, Stengel A, Wang L, Taché Y. Central nesfatin-1 reduces the nocturnal food intake in mice by reducing meal size and increasing inter-meal intervals. Peptides. $2011 ; 32: 36-43$. [PubMed: 20933030]

6. Jackson PJ, Douglas NR, Chai B, Binkley J, Sidow A, Barsh GS, et al. Structural and molecular evolutionary analysis of Agouti and Agouti-related proteins. Chem Biol. 2006; 13:1297-305. [PubMed: 17185225]

7. Konczol K, Pinter O, Ferenczi S, Varga J, Kovacs K, Palkovits M, et al. Nesfatin-1 exerts long-term effect on food intake and body temperature. Int J Obes (Lond). 2012

8. Maejima Y, Sedbazar U, Suyama S, Kohno D, Onaka T, Takano E, et al. Nesfatin-1-regulated oxytocinergic signaling in the paraventricular nucleus causes anorexia through a leptin-independent melanocortin pathway. Cell Metab. 2009; 10:355-65. [PubMed: 19883614]

9. Martinez V, Wang L, Rivier J, Grigoriadis D, Taché Y. Central CRF, urocortins and stress increase colonic transit via CRF1 receptors while activation of CRF2 receptors delays gastric transit in mice. J Physiol. 2004; 556:221-34. [PubMed: 14755002]

10. Oh-I S, Shimizu H, Satoh T, Okada S, Adachi S, Inoue K, et al. Identification of nesfatin-1 as a satiety molecule in the hypothalamus. Nature. 2006; 443:709-12. [PubMed: 17036007] 
11. Palasz A, Krzystanek M, Worthington J, Czajkowska B, Kostro K, Wiaderkiewicz R, et al. Nesfatin-1, a unique regulatory neuropeptide of the brain. Neuropeptides. 2012

12. Richard CD, Tolle V, Low MJ. Meal pattern analysis in neural-specific proopiomelanocortindeficient mice. Eur J Pharmacol. 2011; 660:131-8. [PubMed: 21211523]

13. Shimizu H, Oh-I S, Hashimoto K, Nakata M, Yamamoto S, Yoshida N, et al. Peripheral Administration of Nesfatin-1 Reduces Food Intake in Mice: The leptin-independent mechanism. Endocrinology. 2009; 150:662-71. [PubMed: 19176321]

14. Stengel A, Goebel M, Wang L, Rivier J, Kobelt P, Mönnikes H, et al. Central nesfatin-1 reduces dark-phase food intake and gastric emptying in rats: differential role of corticotropin-releasing factor2 receptor. Endocrinology. 2009; 150:4911-9. [PubMed: 19797401]

15. Stengel A, Goebel M, Wang L, Rivier J, Kobelt P, Mönnikes H, et al. Activation of brain somatostatin(2) receptors stimulates feeding in mice: Analysis of food intake microstructure. Physiol Behav. 2010; 101:614-22. [PubMed: 20851136]

16. Stengel A, Taché Y. Minireview: Nesfatin-1--An Emerging New Player in the Brain-Gut, Endocrine, and Metabolic Axis. Endocrinology. 2011; 152:4033-8. [PubMed: 21862618]

17. Stengel A, Wang L, Goebel-Stengel M, Taché Y. Centrally injected kisspeptin reduces food intake by increasing meal intervals in mice. Neuroreport. 2011; 22:253-7. [PubMed: 21386700]

18. Yosten GL, Samson WK. The anorexigenic and hypertensive effects of nesfatin-1 are reversed by pretreatment with an oxytocin receptor antagonist. Am J Physiol Regul Integr Comp Physiol. 2010; 298:R1642-7. [PubMed: 20335376]

19. Yosten GL, Samson WK. Nesfatin-1 exerts cardiovascular actions in brain: possible interaction with the central melanocortin system. Am J Physiol Regul Integr Comp Physiol. 2009; 297:R330 6. [PubMed: 19474390] 


\section{Research Highlights}

- Nesfatin-1 $1_{1-82}$ injected icv reduces dark phase feeding in mice

- The mid-fragment nesfatin-1 $1_{30-59}$ dose-dependently reduces $4-\mathrm{h}$ food intake.I

- The reduction goes along with reduced meal frequency and longer inter-meal interval

- Neither nesfatin-1 $1_{1-29}$ nor nesfatin-1 ${ }_{60-82}$ reduce dark phase food intake

- Nesfatin- $1_{30-59}$ is the active core of nesfatin- $1_{1-82}$ 


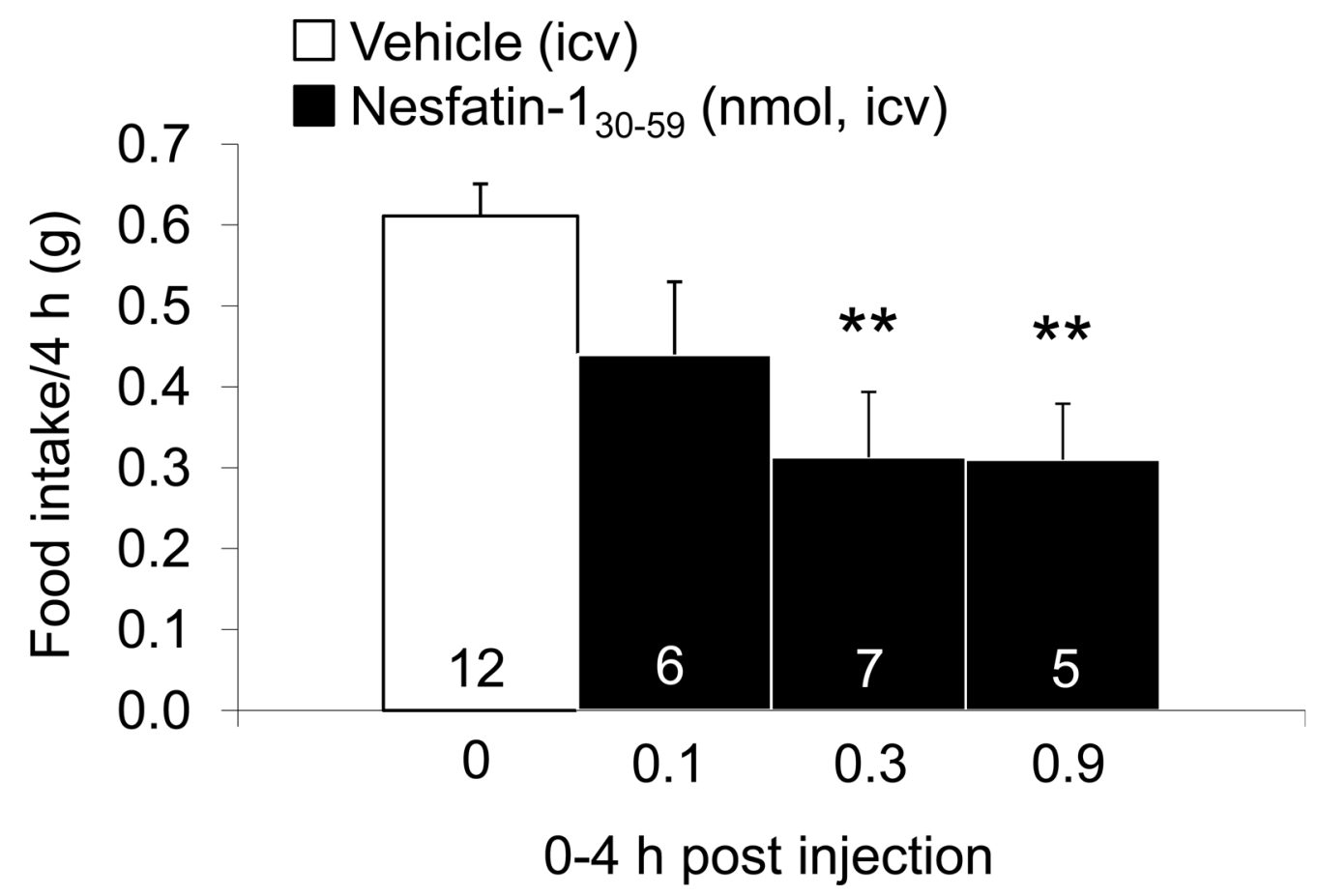

Fig. 1.

Nesfatin-1 $130-59$ injected intracerebroventricularly induces a dose-related decrease in the dark phase food intake in ad libitum fed mice. Nesfatin- $1_{30-59}(0.1,0.3$ or $0.9 \mathrm{nmol} / \mathrm{mouse})$ or vehicle was injected icv under short anesthesia in ad libitum fed non-cannulated mice at the onset of the dark phase. Food intake was assessed for the first 4-h period post icv injection and expressed as cumulative food intake/4 h. Each bar represents the mean \pm SEM of 5-12 mice/group. $* * p<0.01$ vs. vehicle. 
A

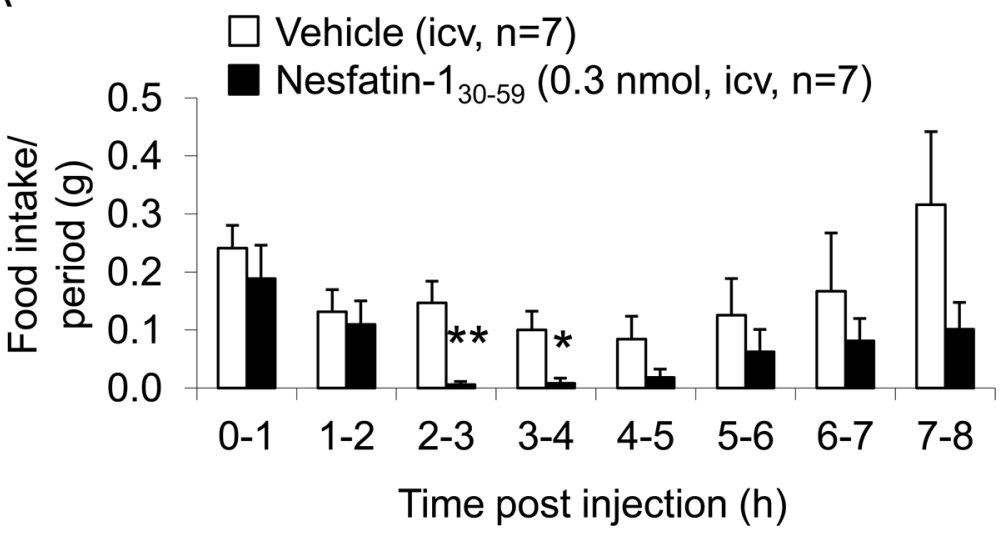

B

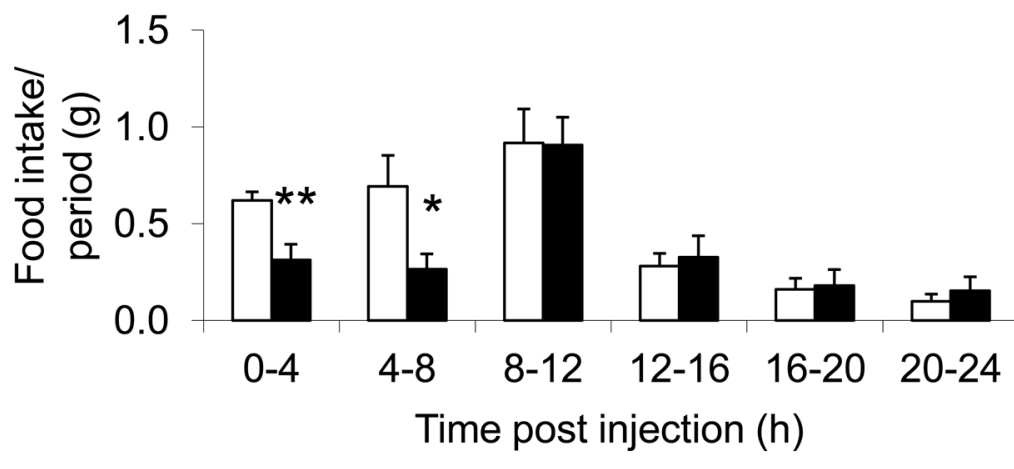

C

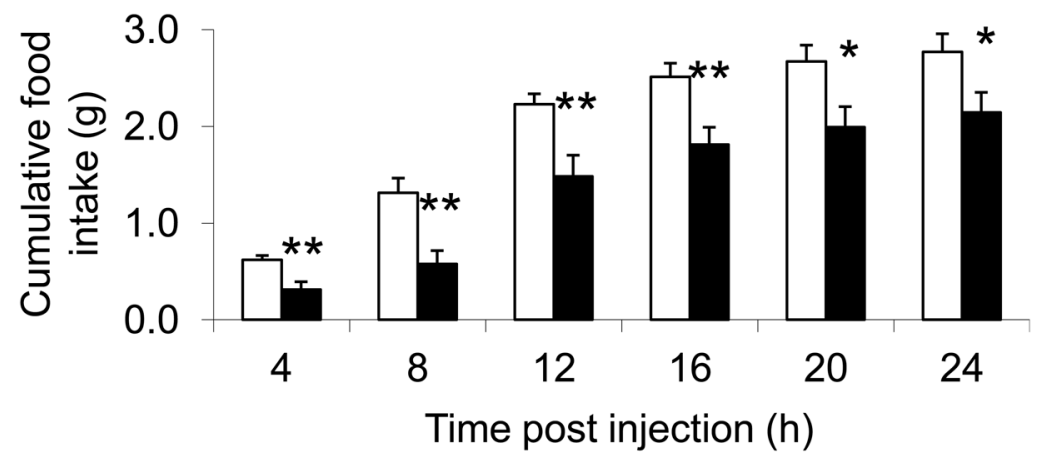

Fig. 2.

Nesfatin-1 $1_{30-59}$ injected intracerebroventricularly decreases food intake in ad libitum fed mice over a period of $24 \mathrm{~h}$. Ad libitum fed non-cannulated mice were injected with nesfatin- $1_{30-59}(0.3 \mathrm{nmol} /$ mouse $)$ or vehicle icv at the onset of the dark phase under short anesthesia and food intake was monitored and expressed as hourly food intake (A), food intake/ 4-h periods (B) and cumulative food intake over a period of $24 \mathrm{~h} \mathrm{(C)}$. Each bar represents the mean \pm SEM of 7 mice/group. $* p<0.05$ and ${ }^{* *} p<0.01$ vs. vehicle. 
A

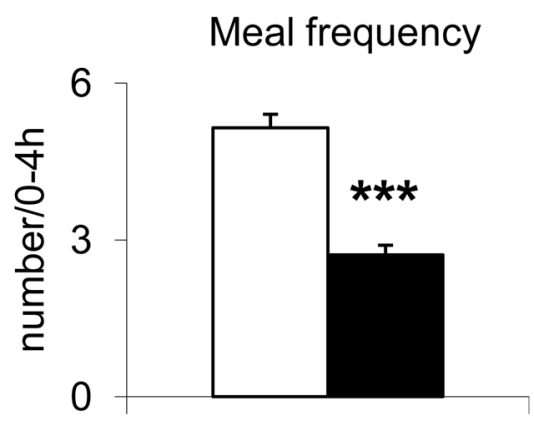

D

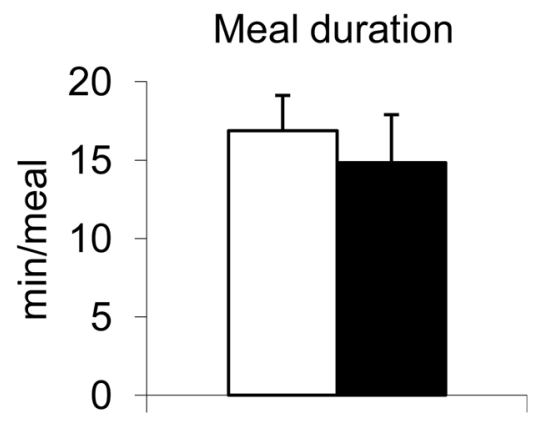

G

Inter-meal interval

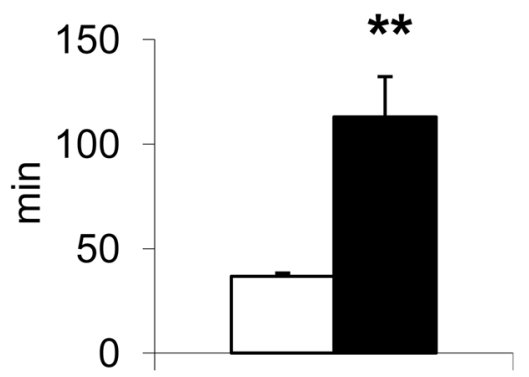

Vehicle (icv, $n=7$ )

Nesfatin-1 ${ }_{30-59}(0.3 \mathrm{nmol}, \mathrm{icv}, \mathrm{n}=7)$
B

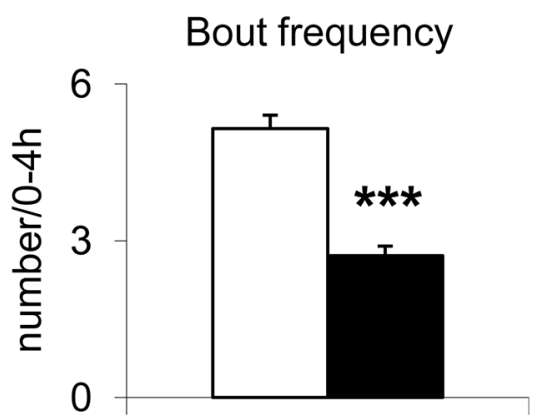

E

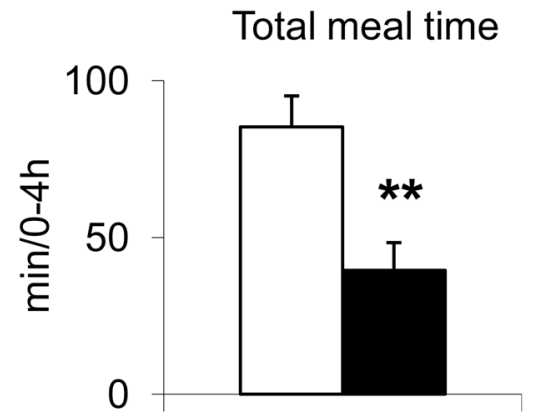

$\mathrm{H}$ Eating rate

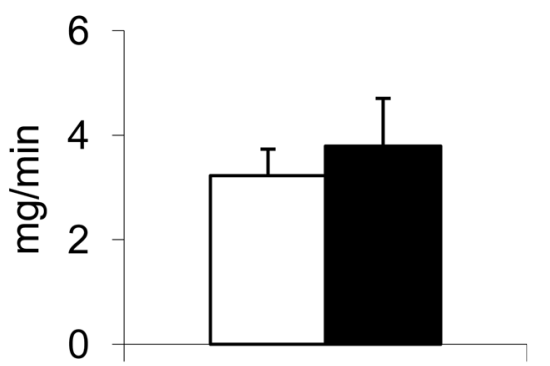

C Meal size

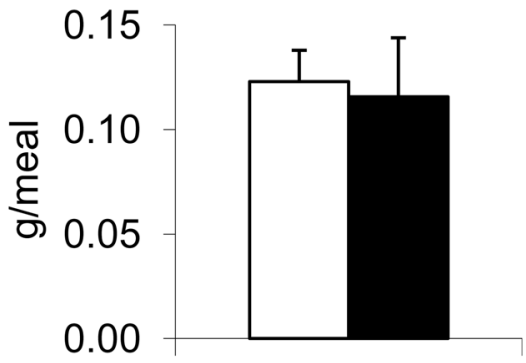

F

Time spent in meals

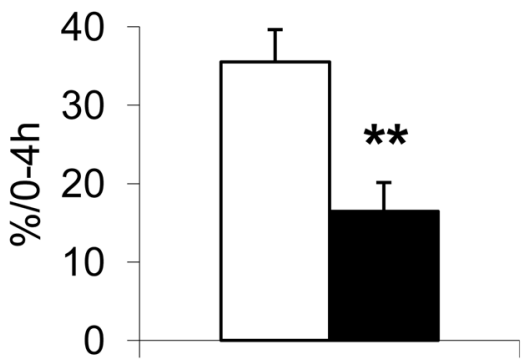

Satiety ratio

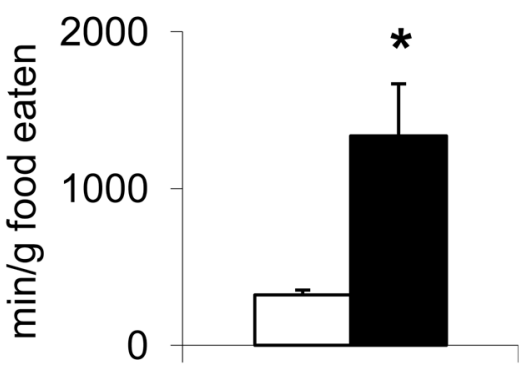

Fig. 3.

Nesfatin-1 $1_{30-59}$ injected intracerebroventricularly decreases meal frequency and increases inter-meal intervals and satiety ratio while not altering meal size during the $0-4 \mathrm{~h}$ period post injection. Nesfatin-1 ( $0.3 \mathrm{nmol} /$ mouse) or vehicle was icv injected in ad libitum fed mice at the onset of the dark phase and feeding microstructure including meal frequency (A), bout frequency (B), meal size (C), meal duration (D), total meal time (E) and time spent in meals $(\mathrm{F})$, inter-meal interval $(\mathrm{G})$, eating rate $(\mathrm{H})$ and the satiety ratio (I) was assessed using an automated episodic food intake monitoring device. Each bar represents the mean \pm SEM of 7 mice/group. $* p<0.05, * * p<0.01$ and $* * * p<0.001$ vs. vehicle. 


\section{Table 1}

Nesfatin-1 ${ }_{30-59}$ injected icv before the dark phase did not significantly influence the structure of the first meal in ad libitum fed mice.

\begin{tabular}{lll}
\hline Parameters & Vehicle (icv) & Nesfatin-1 $\mathbf{3 0 - 5 9}(\mathbf{0 . 3} \mathbf{~ n m o l} / \mathbf{m o u s e}, \mathbf{i c v})$ \\
\hline Latency to $1^{\text {st }}$ meal (min) & $11.1 \pm 3.8$ & $26.9 \pm 13.1$ \\
Duration $1^{\text {st }}$ meal (min) & $28.7 \pm 6.7$ & $18.6 \pm 5.3$ \\
Eating rate $1^{\text {st }}$ meal $(\mathrm{mg} / \mathrm{min})$ & $3.2 \pm 0.5$ & $3.8 \pm 0.9$ \\
\hline
\end{tabular}

Data are mean \pm SEM; $\mathrm{n}=7$ mice/group, $p>0.05$. 
Table 2

Nesfatin-1 $1_{1-29}$ and nesfatin-1 $1_{60-82}$ injected icv did not significantly influence the hourly dark phase food intake during the first $4 \mathrm{~h}$ post-injection in ad libitum fed mice.

\begin{tabular}{|c|c|c|c|c|}
\hline \multirow{2}{*}{ Food intake/period (g) ${ }^{a}$} & \multicolumn{4}{|c|}{ Intracerebroventricular $b$} \\
\hline & Vehicle & Nesfatin-1 $1_{1-29}(0.3 \mathrm{nmol} /$ mouse $)$ & Vehicle & Nesfatin-1 $1_{60-82}(0.3 \mathrm{nmol} / \mathrm{mouse})$ \\
\hline $0-1 \mathrm{~h}$ & $0.24 \pm 0.03$ & $0.16 \pm 0.02$ & $0.28 \pm 0.05$ & $0.35 \pm 0.02$ \\
\hline $1-2 \mathrm{~h}$ & $0.13 \pm 0.03$ & $0.10 \pm 0.02$ & $0.15 \pm 0.04$ & $0.13 \pm 0.04$ \\
\hline $2-3 h$ & $0.14 \pm 0.03$ & $0.15 \pm 0.02$ & $0.15 \pm 0.03$ & $0.08 \pm 0.04$ \\
\hline $3-4 h$ & $0.09 \pm 0.03$ & $0.11 \pm 0.03$ & $0.12 \pm 0.04$ & $0.11 \pm 0.05$ \\
\hline
\end{tabular}

${ }^{a}$ Data are mean \pm SEM; $\mathrm{n}=6-8$ mice/group. $p>0.05$.

${ }^{b}$ Each group had vehicle controls tested at the same time of the nesfatin- 1 fragments. 
Table 3

Meal pattern of dark phase feeding in ad libitum fed mice $0-4 \mathrm{~h}$ after nesfatin- $1_{1-29}$ and nesfatin- ${ }_{60-82}$ injected icv.

\begin{tabular}{|c|c|c|c|c|}
\hline \multirow{2}{*}{ Parameters $^{a}$} & \multicolumn{4}{|c|}{ Intracerebroventricular $b$} \\
\hline & Vehicle & Nesfatin-1 $1_{1-29}(0.3 \mathrm{nmol} / \mathrm{mouse})$ & Vehicle & Nesfatin-1 $1_{60-82}(0.3 \mathrm{nmol} / \mathrm{mouse})$ \\
\hline Meal frequency (number/4h) & $4.9 \pm 0.4$ & $5.7 \pm 0.3$ & $5.3 \pm 0.3$ & $3.8 \pm 0.4^{*}$ \\
\hline Bout frequency (number/4h) & $18.4 \pm 2.0$ & $14.3 \pm 1.2$ & $21.2 \pm 2.2$ & $11.8 \pm 1.6^{*}$ \\
\hline Meal size (g/meal) & $0.13 \pm 0.01$ & $0.09 \pm 0.02$ & $0.13 \pm 0.02$ & $0.18 \pm 0.03$ \\
\hline Meal duration (min/meal) & $16.6 \pm 2.0$ & $9.3 \pm 1.2^{*}$ & $17.5 \pm 2.1$ & $18.0 \pm 4.7$ \\
\hline Total meal time (min/4h) & $80.2 \pm 10.0$ & $52.7 \pm 6.4$ & $91.3 \pm 10.5$ & $65.9 \pm 16.0$ \\
\hline Time spent in meals $(\% / 4 \mathrm{~h})$ & $33.4 \pm 4.2$ & $21.9 \pm 2.7$ & $38.0 \pm 4.4$ & $27.5 \pm 6.7$ \\
\hline Inter-meal interval (min) & $45.4 \pm 8.6$ & $41.2 \pm 0.9$ & $35.2 \pm 2.1$ & $59.7 \pm 11.3^{*}$ \\
\hline Latency to $1^{\text {st }}$ meal $(\mathrm{min})$ & $10.3 \pm 3.4$ & $17.2 \pm 4.0$ & $10.2 \pm 3.4$ & $10.1 \pm 2.1$ \\
\hline Duration $1^{\text {st }}$ meal (min) & $28.6 \pm 5.8$ & $15.1 \pm 3.0$ & $30.8 \pm 6.1$ & $30.3 \pm 8.2$ \\
\hline Eating rate $1^{\text {st }}$ meal $(\mathrm{mg} / \mathrm{min})$ & $3.3 \pm 0.4$ & $3.4 \pm 0.8$ & $3.7 \pm 0.6$ & $4.7 \pm 1.1$ \\
\hline Eating rate/4h (mg/min) & $2.6 \pm 0.2$ & $2.3 \pm 0.3$ & $2.9 \pm 0.3$ & $5.2 \pm 2.1$ \\
\hline $\begin{array}{l}\text { Satiety ratio } 1^{\text {st }} \text { period }(\mathrm{min} / \mathrm{g} \text { food } \\
\text { eaten) }\end{array}$ & $368.8 \pm 54.5$ & $515.2 \pm 126.7$ & $295.8 \pm 36.9$ & $396.2 \pm 121.9$ \\
\hline
\end{tabular}

${ }^{a}$ Data are mean \pm SEM; $\mathrm{n}=6-8$ mice/group.

* $p<0.05$.

${ }^{b}$ Each group had vehicle controls tested at the same time of the nesfatin-1 fragments. 